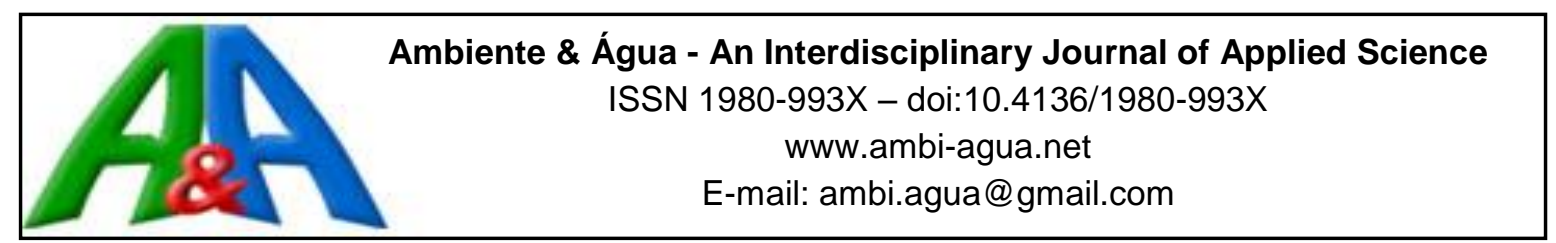

\title{
Qualidade da água utilizada em quiosques de praia
}

\author{
ARTICLES doi:10.4136/ambi-agua.2003
}

Received: 13 Sep. 2016; Accepted: 06 Feb. 2018

\section{Diésse Nascimento Norete; Quezia Botelho Correia; Jackline Freitas Brilhante São José*}

\author{
Universidade Federal do Espírito Santo (UFES), Vitória, ES, Brasil \\ Departamento de Educação Integrada em Saúde. E-mail: diesse.nascimento@ hotmail.com, \\ queziabotelho@hotmail.com, jackline.jose@ufes.br \\ *Autor correspondente
}

\section{RESUMO}

Objetivou avaliar as condições higiênicossanitárias relacionadas ao abastecimento e a qualidade microbiológica da água utilizada por quiosques de praia. A coleta dos dados ocorreu por meio de observação direta com aplicação de lista de verificação que continha itens como procedência da água, realização de tratamento de desinfecção antes do uso em alimentos, frequência de higienização da caixa da água, qualidade microbiológica da água, existência de licença sanitária e registro da última visita da vigilância sanitária. Foram coletadas amostras de água em dez quiosques de praia e para a coleta foram utilizados recipientes esterilizados e identificados. Para contagem de bactérias heterotróficas foi utilizada a técnica de plaqueamento em profundidade em ágar padrão para contagem, sendo os resultados expressos em UFC/mL. Para coliformes foi utilizado o teste do número mais provável (coliformes a $35^{\circ} \mathrm{C}$ e a $45^{\circ} \mathrm{C}$ ) e o resultado obtido foi expresso em NMP/100 mL. Foi observado por meio da aplicação da lista de verificação que $70 \%$ dos quiosques utilizavam apenas água da rede de abastecimento público e um dos estabelecimentos funcionava sem licença sanitária. Das amostras coletadas, $30 \%$ apresentaram contagem total de bactérias acima de $500 \mathrm{UFC} / \mathrm{mL}$. Não foi detectada a presença de coliformes e E. coli em nenhuma das amostras analisadas. Apesar dos resultados observados terem sido satisfatórios, deve-se reforçar a necessidade do acompanhamento da qualidade da água como estratégia de prevenção de riscos aos consumidores.

Palavras-chave: água para consumo, análise de água, coliformes.

\section{Quality of water used by beach kiosks}

\section{ABSTRACT}

This study evaluated the sanitary conditions and the microbiological quality of the water used by beach kiosks. Data was collected through direct observation, using a checklist with such items as water source, disinfection treatment before use, frequency of water container sanitation, microbiological quality of water, existence of sanitary license and records of the last inspection by health authorities. Water samples were collected in labeled, sterilized containers from 10 beach kiosks. The plate technique in depth in standard agar was used for counting heterotrophic bacteria and the results were expressed in CFU/mL. The mostprobable number test was used to evaluate coliforms (coliforms at $35^{\circ} \mathrm{C}$ and $45^{\circ} \mathrm{C}$ ) and the 
results were expressed in NMP/100 mL. It was observed that $70 \%$ of the kiosks used only water from the public supply and one of the establishments operated without a sanitary license. Of the samples collected, $30 \%$ had a total bacterial count above $500 \mathrm{CFU} / \mathrm{mL}$. No presence of coliforms and E. coli. was detected in the samples analyzed. While the results were satisfactory, the study reinforced the need to monitor water quality as a strategy to prevent risks to consumers.

Keywords: analysis of water, coliforms, drinking water.

\section{INTRODUÇÃO}

A água é fundamental para os seres humanos e sua importância para a saúde pública é largamente reconhecida, com a garantia da potabilidade que é essencial para a população (Scorsafava et al., 2013; Volkweis et al., 2015). Destaca-se que a água que será consumida pelo homem não deve conter substâncias dissolvidas em quantidades que causam toxicidade e nem veicular micro-organismos patogênicos causadores de doenças (Santos et al., 2013). Deste modo, a água é própria para o consumo humano quando atende aos parâmetros microbiológicos e físico-químicos das especificações de potabilidade estabelecidas pela Portaria $n^{\circ}$ 2.914/2011 do Ministério da Saúde (MS) (Brasil, 2011). Caso não atenda a estes requisitos, a água pode afetar ou depreciar equipamentos, instalações e, principalmente, favorecer a possibilidade de contaminação e ocorrência de enfermidades aos consumidores (Mouchrek e Carvalho, 2016).

O uso de água sem controle de qualidade pode comprometer a saúde pública de forma a proporcionar riscos individuais ou coletivos, imediatos ou de longo prazo. O consumo de água contaminada, não só para beber, mas também para uso diário, pode acarretar a ocorrência de doenças de transmissão hídrica. Este contexto de negligência colabora para o alto custo e a necessidade de serviços especializados para o tratamento destas doenças (Araújo et al., 2013).

A contaminação da água por micro-organismos patogênicos pode ocorrer principalmente por fezes de origem humana e animal. As enfermidades mais comuns causadas por estes agentes etiológicos são a febre tifóide, febre paratifóide, cólera, disenteria bacilar, diarreias e hepatites (Nkere et al., 2011). A pesquisa de micro-organismos patogênicos na água requer procedimentos complexos e longos, sendo indispensável a utilização de indicadores de contaminação de origem fecal para avaliar a qualidade microbiológica da água. Dentre os principais destacam-se os coliformes totais (coliformes a $35^{\circ} \mathrm{C}$ ), coliformes termotolerantes (coliformes a $45^{\circ} \mathrm{C}$ ) e Escherichia coli (WHO, 2011). Os coliformes a $35^{\circ} \mathrm{C}$ são bacilos gram negativos, aeróbios ou anaeróbios facultativos, não formadores de esporos, oxidase-negativos, e fermentam lactose com produção de ácido e gás. Neste grupo, a maioria pertence aos gêneros Escherichia, Citrobacter, Klebsiella e Enterobacter. Já os coliformes a $45^{\circ} \mathrm{C}$ tem como principal representante a Escherichia coli, de origem exclusivamente fecal (Souza, 2012).

No preparo de alimentos existem muitos procedimentos nos quais o uso da água está envolvido como por exemplo, limpeza e sanitização de alimentos, higienização de mãos de manipuladores, higienização de utensílios e superfícies que entram em contato com alimentos, bem como na cocção dos alimentos (Silveira et al., 2011). Assim, torna-se crucial a potabilidade da água para contribuir para melhor qualidade higiênicossanitária das preparações elaboradas em estabelecimentos comerciais, como os quiosques de praia.

Deste modo, este trabalho teve como objetivo avaliar as condições higiênicossanitárias relacionadas ao abastecimento de água e avaliar a qualidade microbiológica da água utilizada por quiosques de praia. 


\section{MATERIAL E MÉTODOS}

Foi realizado no período de novembro a dezembro de 2014 um estudo transversal, observacional e analítico em quiosques de praia localizados em Vila Velha-ES. Inicialmente, os responsáveis pelos estabelecimentos foram contatados por meio de carta convite para apresentação dos objetivos da pesquisa e, em seguida foi solicitada a permissão para visita, aplicação da lista de verificação e coleta das amostras de água.

Dos 30 quiosques existentes no local estudado, dez concordaram em participar da pesquisa, representando $33,33 \%$ do número total de estabelecimentos.

\subsection{Aplicação da Lista de Verificação}

A coleta dos dados ocorreu por meio de observação direta durante as visitas realizadas por pesquisadores treinados. Foi aplicada uma lista de verificação, baseada nos itens relacionados ao abastecimento de água contidos na Resolução 216/2004 do Ministério da Saúde (Anvisa, 2004). A lista de verificação foi composta por 10 itens que estavam relacionados à procedência da água; à realização de tratamento de desinfecção antes do uso em alimentos (para preparo ou higienização, por exemplo), e no caso de realização de tratamento prévio quem era o responsável pelo procedimento; à frequência de higienização da caixa da água: se realizava e com que frequência era efetuado o acompanhamento da qualidade microbiológica da água; existência de licença sanitária; e registro da última visita da vigilância sanitária. Em cada visita realizada os pesquisadores permaneceram aproximadamente por uma hora, durante o funcionamento do estabelecimento, para observação dos itens presentes na lista de verificação bem como checagem de registros disponíveis.

\subsection{Análise Microbiológica das Amostras de Água}

Foram realizadas coletas de amostras de águas em 10 quiosques de praia, sendo incluídos estabelecimentos que utilizavam ou não águas subterrâneas. Para coleta utilizou-se recipiente esterilizado e devidamente identificado. Nos recipientes esterilizados para coleta de amostras provenientes do abastecimento público foram adicionados substância neutralizante do cloro residual da água. Após a coleta, os frascos foram transportados ao laboratório, em caixas isotérmicas, para execução das análises microbiológicas. O processo de coleta foi precedido por limpeza e descontaminação da superfície das torneiras, com a finalidade de evitar a coleta de água com componentes que não pertencem à amostra. Foram coletadas amostras da água das torneiras da cozinha do estabelecimento.

Realizou-se higienização da torneira com aplicação de álcool a 70\%. Foram realizadas coletas de amostras de água em 10 quiosques $(n=10)$ de praia, sendo incluídos estabelecimentos que utilizavam ou não águas subterrâneas, totalizando 12 amostras de água $(\mathrm{m}=12)$, pois dois quiosques eram abastecidos por duas fontes. Os quiosques foram identificados com números de 1 a 10.

Para as análises, utilizaram-se procedimentos de acordo com American Public Health Association (APHA), descrita no Compendium of Methodos for the Microbiological Examination of Foods (Downes e Ito, 2001).

Foram realizados os seguintes testes: presuntivo para coliformes, confirmativo para coliformes a $35^{\circ} \mathrm{C}$, e confirmativo para coliformes a $45^{\circ} \mathrm{C}$. Alíquotas foram colocadas em séries de três tubos contendo caldo lauril sulfato triptose (LST), com tubo de Duharm invertidos (teste presuntivo) e estes foram incubados a $35^{\circ} \mathrm{C}$ por $24-48 \mathrm{~h}$. Deste modo, a partir dos tubos com leitura positiva (turvação e formação de gás), foram realizados os testes confirmativos para coliformes $35^{\circ} \mathrm{C}$ em caldo Lactose Bile Verdes Brilhante (VB) a $2 \%$ a $35^{\circ} \mathrm{C}$ por $24-48 \mathrm{~h}$, e, coliformes $45^{\circ} \mathrm{C}$ em caldo Escherichia coli (EC) a $45^{\circ} \mathrm{C}$ por $24-48 \mathrm{~h}$. Ao avaliar a combinação de números correspondentes aos tubos que apresentaram resultado 
positivo, foi verificado o Número Mais Provável de acordo com a tabela de NMP, conforme os procedimentos básicos de contagem. O valor obtido foi expresso em NMP/100 mL. Para a contagem total de heterotróficos foi feita semeadura em profundidade em Agar Padrão para Contagem (PCA), sendo os resultados expressos em UFC/mL.

Os resultados obtidos foram analisados e comparados com os padrões previstos na Portaria no 2914 de 2011(Brasil, 2011). Para análise dos dados coletados a partir da lista de verificação foi realizada estatística descritiva com uso de frequência e valores percentuais com auxílio do software Microsoft Office Excel®, 2010.

\section{RESULTADOS E DISCUSSÃO}

Foi observada por meio da aplicação da lista de verificação que $70 \%$ dos quiosques utilizavam apenas água da rede de abastecimento público (Tabela 1). Os demais utilizavam água proveniente da rede de abastecimento público e/ou de poços subterrâneos. Mouchrek e Carvalho (2016), em estudo com serviços de alimentação, também observaram predomínio do abastecimento de água pelo serviço público.

A água de abastecimento público é um recurso hídrico que deve ser retirado da natureza e oferecido à população em quantidade e qualidade adequadas. Esta água pode ser proveniente de diferentes fontes como água de superfície (lagos, rios e açudes) e águas do lençol freático que são subterrâneas (Liguori et al., 2010). A água subterrânea é um sistema alternativo de abastecimento e representa $97 \%$ dos recursos hídricos disponíveis ao homem e atende mais da metade da população mundial, principalmente em regiões de clima semiárido (Colvara et al., 2009)

Tabela 1. Frequência do abastecimento de água por serviço público e/ ou poço artesiano em dez quiosques de praia, Vila Velha-ES.

\begin{tabular}{lcc}
\hline Fonte de Abastecimento & Frequência & $\mathbf{\%}$ \\
\hline Público & 7 & 70 \\
Público + Poços artesianos & 2 & 20 \\
Poços artesianos & 1 & 10 \\
\hline
\end{tabular}

Quanto ao tratamento prévio à utilização da água, verificou-se que apenas $10 \%$ dos quiosques realizavam tal procedimento. Ressalta-se que este estabelecimento era o mesmo que utilizava água proveniente de poços artesianos. Assim, entende-se que a maioria os donos dos estabelecimentos confiavam na qualidade da água que recebiam por meio do abastecimento público. Aqueles que tomavam precauções com relação a tratamentos de água realizavam procedimentos como a fervura ou a adição de hipoclorito de sódio antes do uso em alimentos.

Quanto à frequência da limpeza da caixa d’água, foram consultados registros, sendo observado que $70 \%$ dos quiosques realizavam a cada 6 meses e este procedimento era realizado pelo próprio responsável pelo estabelecimento. Estes quiosques eram os mesmos que utilizavam apenas água proveniente do abastecimento público. Os demais estabelecimentos realizavam a cada dois meses, o que indica maior preocupação destes com o controle de qualidade da água. Os resultados do presente estudo foram superiores ao observado por Silveira et al. (2011) que verificaram que somente 18,8\% das escolas avaliadas tinham reservatório de água em condições adequadas com limpeza semestral. Segundo a legislação vigente sobre boas práticas para serviços de alimentação (Anvisa, 2004), o reservatório de água deve ser edificado e mantido em perfeito estado de higiene e conservação de modo que a qualidade da água não seja afetada. $\mathrm{O}$ procedimento de higienização do 
reservatório deve ser realizado em um intervalo máximo de seis meses e devem ser feitos registros da operação. Quando este procedimento for realizado por empresa terceirizada é necessária a apresentação de certificado de execução do serviço (Anvisa, 2004).

O controle de qualidade da água para uso na produção de alimentos é imprescindível para reduzir riscos à saúde dos consumidores. Portanto, a água deve ser potável, e para manter a qualidade é necessário que o reservatório esteja íntegro, limpo e tapado, bem como, deve ser realizado periodicamente o acompanhamento da qualidade microbiológico da água (Portugal et al., 2015).

Com relação às análises microbiológicas da água utilizada nos quiosques, 50\% destes realizavam coleta e encaminhavam amostras para análise pelo menos uma vez ao ano. Vale destacar que este controle da qualidade microbiológica era realizado por quiosques que recebiam água do abastecimento público. Entretanto, os laudos de potabilidade não estavam disponíveis no local. No estudo de Silveira et al. (2011), somente 20,5\% das escolas apresentavam o laudo de potabilidade da água. Verificou-se que $10 \%(\mathrm{n}=1)$ dos quiosques não apresentavam alvará emitido pela Vigilância Sanitária. Quanto ao registro da última visita realizada pela Vigilância Sanitária no estabelecimento, $80 \%$ dos quiosques haviam recebido a fiscalização há mais de seis meses.

Os resultados das análises microbiológicas estão apresentados na Tabela 2. Verifica-se que todas as amostras de todos os quiosques (100\%) atenderam ao padrão para coliformes $35^{\circ} \mathrm{C}$ e $45^{\circ} \mathrm{C}$, estabelecido pela legislação vigente. $\mathrm{O}$ consumo de água precisa atender a padrões de potabilidade recomendados pelos órgãos regulamentadores e trata-se de uma ação de política pública para a prevenção de doenças e redução da mortalidade, por ser um solvente universal e utilizado na produção de alimentos (Mouchrek e Carvalho, 2016), como em quiosques de praia.

Castro (2013) observou que para as amostras analisadas em restaurantes, dois estabelecimentos apresentaram água fora do padrão microbiológico exigido pela legislação vigente. Mouchrek e Carvalho (2016), ao avaliar amostras de água de oito serviços de alimentação (sendo quatro lanchonetes e quatro restaurantes), observaram que em $75 \%$ ( $n=6$ ) dos estabelecimentos visitados apresentavam água com qualidade microbiológica adequada.

A análise de bactérias heterotróficas não é um parâmetro exigido pela legislação brasileira relacionada à potabilidade de água para consumo humano, mas permite avaliar a qualidade da água utilizada tanto para cocção dos alimentos quanto para higienização de mãos, de superfícies e dos alimentos. Em estudo realizado por Vasconcelos et al. (2015), com água de bebedouros de três Campi da Universidade Federal do Ceará, foram analisadas amostras de água de cinco bebedouros, e obteve-se 6 amostras de águas contaminadas que correspondiam a 2 bebedouros, cujos números de bactérias heterotróficas encontradas estavam acima do limite permitido, sendo este achado diferente do registrado no presente estudo.

Segundo a Portaria 2914/2011 (Brasil, 2011), alterações bruscas ou acima do normal na contagem de bactérias heterotróficas necessitam ser averiguadas para identificação de irregularidade e providências devem ser tomadas para restaurar a integridade do sistema de distribuição, sendo indicado que não se ultrapasse $500 \mathrm{UFC} / \mathrm{mL}$. Das amostras analisadas, $50 \%(\mathrm{~m}=6)$ apresentaram contagem superior ao recomendado para bactérias heterotróficas, sendo que metade $(m=3)$ destas eram amostras provenientes de poços subterrâneos. Resultado semelhante foi observado por Silveira et al. (2011) que verificaram que em três escolas a água utilizada apresentou contagem superior a $500 \mathrm{UFC} / \mathrm{mL}$.

Apesar do resultado observado no presente estudo, vale ressaltar que no Brasil entre 1999 e 2008 foram notificados 343 surtos relacionados ao consumo de água, sendo a origem deste desconhecida (Brasil, 2008). O controle da qualidade da água para consumo humano é um conjunto de ações exercidas de forma continuada, destinadas a averiguar se a água fornecida à 
população é potável, de forma a assegurar a manutenção desta condição (Castro, 2013). A água que é utilizada para o consumo direto ou no preparo dos alimentos deve ser controlada independente das rotinas de manipulação dos alimentos (Anvisa, 2004). A água é rotineiramente utilizada para a lavagem de frutas e hortaliças com objetivo de obter alimento microbiologicamente seguro (Abreu et al., 2010). Sendo assim, é imprescindível que a água utilizada seja de qualidade.

Destaca-se ainda que $30 \%(n=3)$ dos quiosques utilizavam águas provenientes de poços subterrâneos. Segundo Queiroz et al. (2002) populações que dependem de fontes alternativas, como poços, estão expostas a maiores contaminações. Apesar disso, no presente estudo nenhuma das amostras de poços foi considerada imprópria. Este resultado difere-se do observado por Araújo et al. (2013) que constataram que $75 \%$ dos poços avaliados apresentaram água imprópria para consumo devido à presença de coliformes a $35^{\circ} \mathrm{C}$ e coliformes $45^{\circ} \mathrm{C}$ acima do preconizado.

Tabela 2. Determinação de coliformes a $35^{\circ} \mathrm{C}$, a $45^{\circ} \mathrm{C}$ e contagem de bactérias heterotróficas de amostras de águas coletadas em quiosques de praia, Vila Velha-ES.

\begin{tabular}{|c|c|c|c|c|c|}
\hline $\begin{array}{l}\text { Amostras de } \\
\text { água }\end{array}$ & Quiosque & Origem & $\begin{array}{l}\text { Coliformes a } 35^{\circ} \mathrm{C} \\
(\mathrm{NMP} / 100 \mathrm{~mL})\end{array}$ & $\begin{array}{l}\text { Coliformes a } 45^{\circ} \mathrm{C} \\
(\mathrm{NMP} / 100 \mathrm{~mL})\end{array}$ & $\begin{array}{l}\text { Contagem de Bactérias } \\
\text { Heterotróficas (UFC/mL) }\end{array}$ \\
\hline 1 & 1 & $\begin{array}{c}\text { Rede de } \\
\text { Abastecimento }\end{array}$ & $<1,0$ & $<1,0$ & $1,0 \times 10^{2}$ \\
\hline 2 & 1 & Poço subterrâneo & $<1,0$ & $<1,0$ & $1,3 \times 10^{3}$ \\
\hline 3 & 2 & $\begin{array}{c}\text { Rede de } \\
\text { Abastecimento }\end{array}$ & $<1,0$ & $<1,0$ & $2,0 \times 10^{2}$ \\
\hline 4 & 3 & $\begin{array}{c}\text { Rede de } \\
\text { Abastecimento }\end{array}$ & $<1,0$ & $<1,0$ & $6,0 \times 10^{2}$ \\
\hline 5 & 4 & $\begin{array}{c}\text { Rede de } \\
\text { Abastecimento }\end{array}$ & $<1,0$ & $<1,0$ & $2,0 \times 10^{2}$ \\
\hline 6 & 4 & Poço subterrâneo & $<1,0$ & $<1,0$ & $2,9 \times 10^{3}$ \\
\hline 7 & 5 & $\begin{array}{l}\text { Rede de } \\
\text { Abastecimento }\end{array}$ & $<1,0$ & $<1,0$ & $5,0 \times 10^{2}$ \\
\hline 8 & 6 & $\begin{array}{c}\text { Rede de } \\
\text { Abastecimento }\end{array}$ & $<1,0$ & $<1,0$ & $1,1 \times 10^{2}$ \\
\hline 9 & 7 & $\begin{array}{c}\text { Rede de } \\
\text { Abastecimento }\end{array}$ & $<1,0$ & $<1,0$ & $2,1 \times 10^{2}$ \\
\hline 10 & 8 & $\begin{array}{c}\text { Rede de } \\
\text { Abastecimento }\end{array}$ & $<1,0$ & $<1,0$ & $5,7 \times 10^{2}$ \\
\hline 11 & 9 & Poço subterrâneo & $<1,0$ & $<1,0$ & $2,3 \times 10^{3}$ \\
\hline 12 & 10 & $\begin{array}{c}\text { Rede de } \\
\text { Abastecimento }\end{array}$ & $<1,0$ & $<1,0$ & $1,2 \times 10^{3}$ \\
\hline
\end{tabular}

* Padrão microbiológico para água para consumo humano no sistema de distribuição (reservatórios e rede) estabelecido pela Portaria 2914/2011: Escherichia coli- Ausência em 100 mL; Coliformes totais: Ausência em $100 \mathrm{~mL}$ em 95\% das amostras examinadas (Sistemas ou soluções alternativas coletivas que abastecem a partir de 20.000 habitantes).

As águas extraídas por poços têm sido cada vez mais utilizadas para o consumo humano, pois são de fácil obtenção e custo, principalmente para pessoas que não tem acesso à rede pública de abastecimento. Porém, este tipo de abastecimento pode se tornar uma preocupação devido ao fato de muitas vezes estarem próximas às residências, onde podem ser contaminados por dejetos humanos e de animais (Volkweis et al., 2015). As principais causas de contaminação da água de poços estão relacionadas à entrada de impurezas por meio do procedimento de abertura superior do poço, contaminação na ocasião da retirada de água, infiltração de águas de enxurradas de locais próximos ao poço, fossa negra ou poço absorvente (Souza, 2012). Quiosques que utilizam água de poço sem o tratamento para garantir a potabilidade põem em risco à qualidade dos alimentos servidos (Portugal et al., 2015).

Destaca-se que a recusa dos demais quiosques quanto à participação da pesquisa e 
autorização para as coletas possa estar relacionada à falhas no controle de qualidade de água reconhecidas pelos próprios responsáveis pelo estabelecimento.

Ao final do desenvolvimento da pesquisa foram apresentados os resultados das análises aos responsáveis pelos estabelecimentos e houve esclarecimento quanto à necessidade da manutenção da qualidade da água utilizada para promoção da saúde pública.

\section{CONCLUSÃO}

Os resultados obtidos a partir da lista de verificação indicam que a maioria dos estabelecimentos tem preocupação com a qualidade da água utilizada. A análise microbiológica das amostras de água não revelou resultados preocupantes, mas não se deve desconsiderar a necessidade do acompanhamento pelos órgãos competentes para verificação ao atendimento a legislação vigente.

\section{REFERÊNCIAS BIBLIOGRÁFICAS}

ABREU, I. M. O.; JUNQUEIRA, A. M. R.; PEIXOTO, J. R.; OLIVEIRA, S. A. Qualidade microbiológica e produtividade de alface sob adubação química e orgânica. Ciência e Tecnologia de Alimentos, v. 30, supl. 1, p. 108-118, maio 2010. http://dx.doi.org/10.1590/S0101-20612010000500018

AGÊNCIA NACIONAL DE VIGILÂNCIA SANITÁRIA - ANVISA (Brasil). Resolução RDC no 216 de 15 de setembro de 2004. Dispõe sobre o Regulamento Técnico de Boas Práticas para Serviços de Alimentação. Diário Oficial [da] União, Brasília, 16 set. 2004.

ARAÚJO, C. F.; HIPOLITO, J. R.; WAICHMAN, A. V. Avaliação da qualidade da água de poço. Revista do Instituto Adolfo Lutz, v. 72, n. 1, p. 53-58, 2013.

BRASIL. Ministério da Saúde. Portaria nº 2.914, de 12 de dezembro de 2011. Dispõe sobre os procedimentos de controle e de vigilância da qualidade da água para consumo humano e seu padrão de potabilidade. Diário Oficial [da] União, Brasília, 14 dez. 2011.

BRASIL. Ministério da Saúde. Secretaria de Vigilância em Saúde. Surtos de DTA ocasionados por água. 2008. Disponível em: http://portal.saude.gov.br/portal/arquivos/pdf/surtos_agua_10.pdf. Acesso 2016.

CASTRO, R. S. D. Boas práticas de fabricação (BPF) análise de tomate e água em restaurantes comerciais da cidade de Botucatu-SP. 2013 Tese (Doutorado] Universidade Estadual Paulista Júlio de Mesquita Filho, Botucatu, 2013.

COLVARA, J. G.; LIMA, A. S.; SILVA, W. P. Avaliação da contaminação de água subterrânea em poços artesianos no sul do Rio Grande do Sul. Brazilian Journal of Food Technology, v. 2, p. 11-14, 2009.

DOWNES F. P.; ITO K. Compendium of methods for the microbiological examination of foods. 4. ed. Washington D.C. APHA, 2001. p. 25-26.

LIGUORI, G.; CAVALLOTTI, I.; ARNESE, A. et al. Microbiological quality of drinking water from dispensers in Italy. BMC Microbiology, v. 10, n. 19, p. 1-5, 2010. https://doi.org/10.1186/1471-2180-10-19 
MOUCHREK, A. N.; CARVALHO E. C. C. Qualidade da água em serviços de alimentação de um bairro da zona rural de São Luís, Maranhão, Brasil. Revista Brasileira de $\begin{array}{llllll}\text { Pesquisa } & \text { em } & \text { Saúde, } & \text { v.18, } & \text { n.3, }\end{array}$ https://doi.org/10.21722/rbps.v18i3.15752

NKERE, C. K.; IBE, N. I.; IROEGBU, C. U. Bacteriological Quality of Foods and Water Sold by Vendors and in Restaurants in Nsukka, Enugu State, Nigeria: A Comparative Study of Three Microbiological Methods. Journal of Health, Population and Nutrition, v. 29, n.6, p.560-566, 2011.

PORTUGAl, A. S. B.; IUlianello, J. M.; GOLTARA, M. C. A.; MEDEIROS, L. S.; SILVA, E. M. M; SÃO JOSÉ, J. F. B. Condições Higiênicossanitárias em Quiosques de Praia em Vila Velha-ES. DEMETRA: Alimentação, Nutrição \& Saúde, v. 10, p. 845856, 2015. https://doi.org/10.12957/demetra.2015.16723

QUEIROZ, M. F.; CARDOSO, M. C. S.; SANTANA, E. M.; GOMES, A. B.; RIQUE, S. M. N.; LOPES, C. M. A qualidade da água de consumo humano e as doenças diarréicas agudas no Município do Cabo de Santo Agostinho, PE. Revista Brasileira Epidemiologia, supl. esp., p. 456-462, 2002.

SANTOS, J. O.; SANTOS, R. M. S.; GOMES, M. A. D.; MIRANDA, R. C.; NÓBREGA, I. G. M. A qualidade da água para o consumo humano: Uma discussão necessária. Revista brasileira de Gestão Ambiental-RBGA, v. 7, n. 2, p. 19-26, 2013.

SOUZA, M. Qualidade da água utilizada em serviço de alimentação de hotéis. 2012. 83f. Tese (Doutorado em Ciência Veterinária) - Universidade Federal Rural de Pernambuco, Recife, 2012.

SCORSAFAVA, M. A.; SOUZA, A.; STOFER, M.; NUNES, C. A.; MILANEZ, T. V. Qualidade físico-química da água de abastecimento da região do Vale do Ribeira-SP, Brasil. Revista do Instituto Adolfo Lutz, v. 72, n. 1, p. 81-86, 2013.

SILVEIRA, J. T.; CAPAlONGA, R.; OLIVEIRA, A. B. A.; CARDOSO, M. R. I. Avaliação de parâmetros microbiológicos de potabilidade em amostras de água provenientes de escolas públicas. Revista do Instituto Adolfo Lutz, v. 70, n. 3, p. 362 -367, 2011.

VASCONCELOS, T. S.; MELO, M. B.; FONTENELLE R. O. S. Qualidade microbiológica e físico-química da água de bebedouros consumida por estudantes da Universidade Federal do Ceará. Higiene Alimentar, v. 29, n. 64, p. 246-247, 2015.

VOLKWEIS, D. S. H.; LAZZARETTI, J.; BOITA, E. R. F.; BENETTI, F. Qualidade microbiológica da água utilizada na produção de alimentos por agroindústrias familiares do município de Constantina/RS. Revista Eletrônica em Gestão, Educação e Tecnologia Ambiental, v. 19, n. 1, p. 18-26, 2015. http://dx.doi.org/105902/22361170 19182

WORLD HEALTH ORGANIZATION. Guidelines for Drinking Water Quality. 4th Ed. Geneva, 2011. 